This is a so-called personal version (author's manuscript as accepted for publishing after the review process but prior to final layout and copyediting) of the article:

Vaara, Eero. 2001. Role-bound actors in corporate combinations: a sociopolitical perspective on post-merger change processes. Scandinavian Journal of Management, 17 (4): 481-509.

Researchers are kindly asked to use the official publication in references.

\title{
Role-bound actors in corporate combinations: a sociopolitical perspective on post-merger change processes
}

\author{
Eero Vaara \\ Department of International Business \\ Helsinki School of Economics and Business Administration \\ Runeberginkatu 14-16, 00100 Helsinki, Finland
}




\begin{abstract}
Real-life experiences of corporate mergers often tell of disappointment in terms of the synergistic benefits that fail to appear, or the severe organisational problems that arise. Although many studies have provided empirical material on internal divisions among actors coming from the previously separate organisations, we still know little about the sociopolitical forces at work in the upper echelons of corporate hierarchies. It is suggested in this paper that an examination of the emergent role identities in the upper echelons of a new corporate hierarchy can help us to understand the nature of these sociopolitical forces. The empirical analysis concentrates on a revealing merger case where Finnish Ovako and Swedish SKF Steel first joined forces, but where their organisational marriage broke down five years later. This analysis illustrates how behaviour consistent with the enacted role identities can create contradictory sociopolitical forces, and how this can lead to increasing tension and severe open conflict. The analysis suggests that a favourable turn in the business cycle is a condition that can easily hide such divisions with dramatic consequences later on.
\end{abstract}

Keywords: Merger; Integration:Organisational change; Corporation; Role; Identity

Mergers $^{1}$ that create new corporations by combining previously separate companies operating in the same or similar businesses have become increasingly common. However, the experiences that follow mergers frequently tell of internal problems in the subsequent change processes (Buono \& Bowditch, 1989; Larsson, 1990; Haspeslagh \& Jemison, 1991; Greenwood, Hinings \& Brown, 1994; Olie, 1994). It is also a common experience that internal decision making processes tend to be highly politicised in these developing organisations, as reflected in such things as the managers' status and departures (Hambrick \& Cannella, 1993).

The concept of unified management has nonetheless dominated the literature on organisational integration following mergers and acquisitions (Haspeslagh \& Jemison, 1991; Pablo, 1994). A number of studies have concentrated mainly on the question of how to manage the organisational forces of resistance while paying little attention to internal divisions among key decision makers (Buono \& Bowditch, 1989). Such studies as have looked at internal divisions have generally limited themselves to the basic division between organisational members from the organisations that were previously separate (Buono \& Bowditch, 1989; Greenwood et al., 1994; Olie, 1994). As a result, we know very little about the internal structuration and sociopolitical forces in the upper echelons of the corporate 
hierarchy. This is obviously a serious deficiency if we want to understand why mergers often fail to deliver the synergistic benefits sought, and why they tend to create internal organisational problems.

This paper concentrates on international decision-making processes in an emerging corporation created as a result of a merger. The starting point is that decision makers in large corporate organisations do not form a coherent whole; rather, they are divided according to their national, professional, gender and ethnic backgrounds and by their different positions in the corporate system (see Miller, Hickson \& Wilson, 1996). This is reflected both in the expectations that others impose on these actors, thus creating different types of roles, and the way the actors identify themselves. The approach adopted here is to concentrate on the emerging role-structure in the upper echelons of the new corporate hierarchy. Although role theory has been the subject of much serious debate in recent decades (see Turner, 1985), it is argued here that focusing on the enactment of role identities can help us to understand key decision makers in internal discussions concerning major organisational changes.

The empirical analysis focuses on a revealing merger case in which Finnish Ovako and Swedish SKF Steel joined forces, only for the organisational marriage to break down five years later. The analysis shows how behaviour that is consistent with the enacted role identities can create contradictory sociopolitical forces, which in turn lead to increasing tension and severe open conflict. The analysis suggests specifically that a favourable turn in the business cycle is a condition that can reinforce such underlying internal divisions.

\section{Research on post-merger organisational change processes}

Although quite early on some researchers had pointed out the importance of the first period following the combining of separate organisations (Kitching, 1967; Levinson, 1970), the discussion of post-merger organisational change processes did not really get going until the 1980s. At that time, several researchers adopted the view that events after completion of the juridical arrangements surrounding a merger or an acquisition are particularly important to our understanding of the organisational consequences of merger decisions. Since then, researchers with a human resource orientation have concentrated on the impact of mergers and acquisitions on employees and other organisational members (Marks \& Mirvis, 1985; Schweiger, Ivanevich \& Power, 1987; Buono \& Bowditch, 1989; Napier, 1989; Cartwright \& 
Cooper, 1993) and have provided valuable insights regarding the mechanisms of resistance to organisational change in such situations (Schweiger et al., 1987; Schweiger \& DeNisi, 1991; Fried, Tiegs, Naughton \& Ashford, 1996). Other studies have examined from a cultural perspective the beliefs and values of the previously separate organisations and have explored the big differences that may exist between them (Altendorf, 1986; Sales \& Mirvis, 1984; Walter, 1985); others have identified these differences as the causes of organisational conflict (Kleppestø, 1993; Olie, 1994), while others have examined the dynamics of the acculturation processes subsequent to mergers and acquisitions (Nahavandi \& Malekzadeh, 1988). More strategically orientated researchers in their turn have examined the way in which the change processes may or may not create significant benefits for the organisations involved (Hunt, 1990; Larsson, 1990; Haspeslagh \& Jemison, 1991; Ingham, Kran \& Lovestam, 1992; Pablo, 1994).

Probably as a result of the increasing popularity of mergers and acquisitions, much of this literature has had rather a normative orientation. Researchers have often tried to develop guidelines for practitioners. Studies with a human resource or a cultural perspective have looked specifically at the way management should act to avoid problems arising from resistance in the work force (Buono \& Bowditch, 1989; Greenwood et al., 1994) or to avert cultural clashes (Nahavandi \& Malekzadeh, 1988; Olie, 1994). Several researchers have found, for example, that the way management takes the views of the work force into consideration is likely to have a powerful effect on possible resistance. The general recommendation for practitioners has been that top-level decision makers should be prepared to make more modest changes in the organisations concerned if the alternative would be serious internal problems (Schweiger et al., 1987; Buono \& Bowditch, 1989). Others have referred specifically to management's communication strategies and have emphasised the importance of keeping employees informed (Perry, 1986; Bastien, 1987; Napier, Simmons \& Stratton, 1989; Schweiger \& DeNisi, 1991). They have stressed that not only the quantity of the information is vital, but also its relevance to the realities. More strategy orientated researchers have tackled such questions as what managers should do to achieve possible synergy benefits (Larsson, 1990) or to create value (Haspeslagh \& Jemison, 1991). From this perspective various models have also been developed for how the management should handle integration and lead change efforts so as to achieve the optimum synergistic benefits or to create the greatest value relative to the problems caused by organisational resistance (Hunt, 1990; Larsson, 1990; Haspeslagh \& Jemison, 1991; Pablo, 1994). 
The normative or managerialist orientation in this field, however, has maintained a somewhat simplified view of the nature of management in the post-merger organisational change processes. With few exceptions, research in this field has in fact endorsed a clear distinction between management as an agency that makes decisions about organisational integration on the one hand, and the subjects of these changes who comprise the organisations concerned. This probably stems from the usual conceptualisation and focus of these studies, whereby the decisions and changes are seen as questions of integration in a model whose relevant entities are (1) the headquarters and a management assumed to be in control of the organisation, and (2) a specific unit representing a fairly coherent organisation either supporting or resisting the changes.

The analytical construction of the 'integration process', which refers to activities specifically performed by management, or otherwise resulting from the joining together of organisations (Shrivastava, 1986; Nahavandi \& Malekzadeh, 1988; Larsson, 1990; Haspeslagh \& Jemison, 1991; Pablo, 1994), has become a legitimate conceptual starting point and focus for most studies in this field. In fact, the rhetoric of "the management of the integration process" has come to dominate the literature, leading for example to the identifying of different types of approaches, modes and designs (Pritchett, 1985; Nahavandi \& Malekzadeh, 1988; Napier, 1989; Hunt, 1990; Larsson, 1990; Olie, 1990; Haspeslagh \& Jemison, 1991; Pablo, 1994). In practice, these approaches closely parallel various typologies created to distinguish between different kinds of mergers and acquisitions. This has had the important effect that the perspective adopted is that of a rational top management in charge of the integration of the previously separate organisations - and, as far as management is concerned, this perspective usually precludes any other.

Most of the research on mergers and acquisitions has in fact addressed these phenomena from an acquisition perspective. The usual design has involved the examination of an acquired unit, with particular attention to its reactions to the actions of the acquirer's management (Buono \& Bowditch, 1989; Haspeslagh \& Jemison, 1991). There are only a few studies that have concentrated on mergers where the previous owners also become owners of the new corporation (Kleppestø, 1993; Olie, 1996).

Studies with a human resource or cultural perspective have generally speaking provided interesting empirical material about the very different interests and values that managers can bring with them from formerly separate organisations (Datta, 1991; Kleppestø, 1993; Olie, 
1996). However, this material has been used mainly to demonstrate how the views of people representing specific organisations or units reflect the variety of cultural beliefs and values prevailing in their previously separate units. Rather surprisingly, the central question as to how top-level managerial decision makers themselves may act as agents pursuing the interests and values of the different units or cultures has not been addressed.

\section{Internal divisions in the upper echelons of the corporate hierarchy: A role identity perspective on the post-merger organisation}

Whereas most people subscribe to the view that a social role is a set of behaviours expected of a person in a particular social position, there is great confusion and ambiguity in the way the concept of "role" has been defined and applied in social science in general (see Turner, 1985) and in management and organisation studies in particular (see Fondas \& Stewart, 1994). Although it is possible to trace many roots of "role theory" (Park, 1927; Mead, 1934; Lewin, 1951; Parsons, 1951; Merton, 1957), there is a significant demarcation between "structuralist" and "interactionist" perspectives when it comes to the concept of the "role". The structuralist perspective emphasises the importance of compliance with the expectations of others regarding an actor's adoption of a particular role. According to this view, it is important to live up to the expectations created by the surrounding macro- and micro-level institutional structures. This can be seen as a play in which the actors perform the roles assigned to them. This does not necessarily refer to conscious efforts to fulfil the expectations; rather, it implies a natural compliance to the invisible structures. Unawareness on the part of actors about the roles they are adopting can in fact be seen as a sign of the institutionalised nature of those roles. According to the interactionist perspective, on the other hand, roles are seen as created in interactions in specific situations. In such interactions, the actors engage in a game, where they create roles (behaviours) that accord well with the expectations of the others. As the others are doing the same thing at the same time, the result is more a question of constructing roles than of conforming to structurally contingent norms.

While many have argued that the structuralist and interactionist positions are not incommensurable paradigms, others have still found the convergence of the two 'competing' theories to be problematic (see Turner, 1985). However, most theorists nowadays agree upon three things. First, separation is essential between `role’ as a cognitive schema that organises one's knowledge about appropriate behaviours, and 'role’ as behaviours conforming to the 
expectations of others. The linkage between them becomes clear in the idea of the 'enactment' of social roles, which means that actors reproduce or recreate roles in social interaction. This enactment may also lead to changes in the role schemas that people possess. Second, roles are not clear-cut either to observers or to those internalizing them. It is thus essential in role analysis to consider the question of role conflicts, which can arise from the imposition of contradictory, unclear or ambiguous expectations. Third, there is a close link with social identity. ${ }^{2,3}$ Internalising the idea of acting according to a role essentially means constructing a role identity. Many of the more institutionally orientated organisational scholars go so far as to claim that these role-derived social identities are the cornerstones of institutions such as organisations (March \& Olsen, 1989; Scott, 1995). This does not mean reducing roles to formal positions in organisations, however, as some of the early organisation literature could be said to do (see Katz \& Kahn, 1978).

What, then, is the value of the role rhetoric to our understanding of organisational decision making processes in new corporate structures? It is argued here that examining the emerging role-structure among key decision makers can help us to understand how decisions concerning organisational integration are made in the upper echelons of corporate hierarchy.

Reflecting the institutionalised form of corporations, corporate decision making is characterised on the one hand by the division of labour between owners and the executive corporate management on the one hand (Berle \& Means, 1932; Chandler, 1977; Williamson, 1996) and between corporate management and the business unit level on the other (Pettigrew, 1973; Mintzberg, 1985; Guth \& MacMillan, 1986; Teulings, 1986; Goold \& Campbell, 1987; Tainio, Lilja \& Räsänen, 1984; Tainio, Räsänen \& Santalainen, 1987; Dutton, Ashford, O'Neill \& Wierba, 1997). Decision making in the institutionalised corporate system can thus be seen as relating to three types of institutionalised role: owners' representatives, members of corporate management and business unit managers.

What is specific to the merger context, however, is that these roles are being created in a situation where the new organisation is being built on the basis of the old ones. In this particular context it is a question of two formerly separate organisations becoming integrated to create a single organisation. As previous studies of mergers have shown, the differences as seen in a cultural perspective, for example, seem to divide the new organisation in a fundamental way (Buono \& Bowditch, 1989; Datta, 1991; Kleppestø, 1993,Olie, 1994), and probably for a long time. Several studies have also provided interesting evidence about how 
this division is reflected in management, although researchers have not often focused on managerial decision making in these processes (Datta, 1991,Kleppestø, 1993; Cartwright \& Cooper, 1993; Greenwood et al., 1994; Fried et al., 1996). Mergers that cross national boundaries are in this respect particularly interesting. In such cases, it is not only the different organisational practices but also the national identities that are likely to unite the people on the same side, and to distinguish the people on the different sides from one another ( [Olie, 1994] and [Olie, 1996] ; Weber, Shenkar \& Raveh, 1996).

After mergers in which the owners of the previously separate organisations join forces, the interests and views of the owners are usually promoted by their representatives on the board of directors (the usual Western model) or in similar organs (Williamson, 1996). What is significant in the merger setting is that the owners' initial motives for joining forces, and their basic interests and views about the future, may be different. Such aspects are also connected with the power relations between the owners. While in some circumstances either side (in the most common case of two owner groups) may emerge as the dominant owner, the situation is particularly interesting when the ownership is divided on a 50-50 basis.

Mergers also create a new corporate management in charge of developing the new corporation. As studies of relations between managers and owners have indicated, managers do not necessarily view the world in the same way as the owners. Many have even suggested that the managers of large corporations in particular may identify themselves with the interests of the corporation more than with the well-being of the owners (Williamson, 1996). In any case, it is very likely that corporate managers will view many internal integration issues in terms of the way they are linked to the development of the corporation. And since the new corporate management probably consists mostly of people from the previously separate organisations, it may also reflect the former divisions between the two. The situation facing the members of corporate management may be schizophrenic; as they are called upon to distance themselves from the side that they identify with.

The situation of the business unit managers in the new developing corporate structure is fundamentally different. In general, these managers are expected to pursue the interests of the units for which they are responsible. In the specific context of the merger their role is likely to be central in the sense that the anticipated or actual changes are very likely to have profound effects on their specific units and on their future in the new corporation. It may be a question of cutbacks or cost reductions, or longer-term decisions about resource allocation. A 
merger often creates a situation whereby previous competition between separate organisations is internalised in the new corporation. For the heads of individual units, for example, this may give rise to conflicting expectations and to behaviour that is different in different contexts. In the unit setting such a person may often be expected to act as the corporation's representative. In internal discussions in the upper echelons of corporate management, however, the same person is expected to pursue the (assumed) interests of the unit.

A view that emerges according to which three ideal types of role identity can be observed at the upper echelons of the new corporate hierarchy, generating different sociopolitical forces, as shown in Table 1.

Table 1. Ideal role-identities and the resulting sociopolitical forces in the upper echelons of corporate hierarchy in post-merger change processes

\begin{tabular}{|c|c|c|c|}
\hline Role-identity & Typical position & $\begin{array}{l}\text { Identifies } \\
\text { primarily with }\end{array}$ & $\begin{array}{l}\text { Sociopolitical force in top-level } \\
\text { decision making }\end{array}$ \\
\hline $\begin{array}{l}\text { Owners' } \\
\text { representative }\end{array}$ & Board member & Owners & $\begin{array}{l}\text { Mechanism whereby the owners' } \\
\text { interests are reflected in corporate } \\
\text { decision making }\end{array}$ \\
\hline $\begin{array}{l}\text { Corporate } \\
\text { manager }\end{array}$ & $\begin{array}{l}\text { Member of the } \\
\text { corporate top } \\
\text { management team }\end{array}$ & $\begin{array}{l}\text { New } \\
\text { corporation }\end{array}$ & $\begin{array}{l}\text { Mechanism whereby the } \\
\text { corporation is being developed }\end{array}$ \\
\hline $\begin{array}{l}\text { Business unit } \\
\text { manager }\end{array}$ & $\begin{array}{l}\text { Member of the } \\
\text { management team of } \\
\text { the unit }\end{array}$ & Their own unit & $\begin{array}{l}\text { Mechanism whereby the interests } \\
\text { of the units are reflected in } \\
\text { corporate decision making }\end{array}$ \\
\hline
\end{tabular}

It should be noted that this enactment of role-identities occurs in a context where there are also likely to be other significant divisions among the decision makers, connected with such things as their professional, gender or ethnic backgrounds (see Nkomo and Cox, 1996 for a 
discussion of diverse identities in organisations). Personal characteristics and aspirations are also very important in such contexts. Hambrick and Cannella (1993), for example, have argued that the actors are engaged in a game where the stakes concern their positions and careers.

\section{Design of the empirical research}

The empirical part of this paper presents an in-depth analysis of decision making in a merger case in which two steel manufacturers, one Finnish and one Swedish, were joined together, only for the organisational marriage to break down five years later. The specific purpose of this analysis is to illustrate how the basic division of management outlined in this paper can create conflicting social forces, resulting in increasing tension and even severe open conflict within the top management of the new corporation.

The assumption underlying the chosen methodology is that by examining of a carefully selected case from a theoretically grounded perspective, structures or mechanisms inherent to the phenomena being studied can be revealed (Sayer, 1992). Such analysis can then lead to analytical generalisations, that is to say, to findings which upon due reflection can be generalised beyond the particular case (Tsoukas, 1989).

In this light, the selection of a particularly revealing case makes sense. This industrial crossborder merger was followed by internal debate about the future of the previously separate units, leading to overt conflicts and culminating in the re-division of the corporation. Since dramatic developments of this kind are likely to make any divisions or differences in the management more transparent than more stable circumstances would have done, this case can be regarded as a particularly fruitful setting for examining role-enactment in the upper echelons of a corporate hierarchy. There is also a specific value in the fact that this case carries the stigma of failure. The cases that researchers in this field have examined, or been allowed to study in detail, have almost exclusively carried a label of moderate success at least. There is consequently an underlying bias in research on mergers and acquisitions that this analysis can at least partially seek to remedy.

The core of the empirical material in this study comprises in-depth interviews with the "key decision makers” involved in the case. In practice, all those who had been involved in making 
important decisions at the top levels of the corporate hierarchy in the change processes following the decision to merge, were interviewed. The formal positions of these interviewees typically comprised members of the board of directors of the new corporation, members of the different executive committees of the corporate management, or managers of the largest units in the corporation.

Thirty-one top-level decision makers were interviewed altogether. Of these, 20 were Finnish, 10 Swedish and one Norwegian. A total number of 46 interviews were held. The interviews usually lasted for 2 or $3 \mathrm{~h}$. The shortest lasted little more than an hour, and the longest more 6 hs. With few exceptions only (with the request of the subjects concerned), the interviews were tape-recorded and further analysed in written form. It should be noted that most of the interviews were followed by further questions on the telephone or by mail. The interviewees were also given several opportunities to comment on the results of the analysis, which often led to new insights.

The questions asked, and the other methods employed, changed from interview to interview. Most of the interviews, however, involved an attempt to get the interviewee to tell his story of the change processes that followed the merger, paying particular attention to how successful the changes had appeared to be at different stages. This kind of approach, whereby the interviewer tries not to guide the interviewee too much, can be described as `story telling' (see also Alasuutari, 1995). ${ }^{4}$

The interviews were held retrospectively. This naturally meant that the interviewees could only give retrospective accounts of what had happened, and what they had thought or felt at different stages in the change processes. This raises the question of retrospective reconstruction (see Barley, 1990; [Golden, 1992] and [Golden, 1997] ), which was a methodological problem in this analysis. However, the fact that some time had elapsed after the dissolution of the company helped our subjects to accept the idea of in-depth research into what were often painful memories. It was also a necessary condition for their agreeing that the case could eventually be published.

In addition to these in-depth interviews with the managers involved, it was crucial to get access to many kinds of documentary material, including published information such as annual reports, brochures, press releases and articles concerning the organisations concerned. More importantly, the material also included unpublished material provided by those 
involved, such as the minutes of meetings, more or less formal plans, all kinds of financial and technical reports, copies of various presentations, memos, letters and even notes in personal diaries. The analysis of this material revealed a great deal about the actual course of the decision making processes, and helped to place the interviewees' retrospective accounts in context.

\section{A sociopolitical perspective on post-merger decision making processes in the case of Ovako Steel}

\subsection{The creation of Ovako Steel}

Ovako was a Finnish steel corporation that had been built up by combining the privately owned Finnish steelworks through mergers and acquisitions during the 1970s. Ovako's principal owners were companies belonging to a specific owner bloc in Finland. An important part of the organisation was the Imatra steel-mill that made special steel products. Another important unit was the Koverhar steel-mill that made commercial steel products.

At the beginning of the 1980s Ovako had undergone a process of reorganisation. As a result of this process, the company was able to report quite good profitability between 1983 and 1985, for example. It was clear to the owners and the top management, however, that the Imatra production unit required modernisation and, consequently substantial investment, to remain competitive in the industry. The Ovako owners no longer regarded the steel industry as a core business in their portfolio. So together with the top management they began looking at different alternatives that could help to finance the necessary investments and gradually to reduce the owners' involvement in the steel industry.

SKF Steel was part of the large Swedish SKF corporation, answering for steel production operations. SKF was the world's largest manufacturer of roller bearings. A considerable portion of SKF Steel's production volume was sold to the bearing plants of the parent corporation. The core of SKF's organisation were the large production units in Hellefors and Hofors.

SKF's top management had long been dissatisfied with SKF Steel, whose profitability had been rather poor. It was estimated that a reduction in capacity on the one hand, and new investment on the other, would be required to make the company profitable in the long run. 
The ongoing restructuring of the European steel industry which meant the creation of larger steel corporations, was also seen as a future threat. From SKF's perspective, SKF Steel was no longer a core business. However, SKF wanted to secure the future of SKF Steel because the availability of certain types of steel in Sweden was considered crucial to SKF's core business, namely the production of roller bearings.

At the end of 1985, after various negotiations, the owners and top management of Ovako and the owners and top management of SKF Steel began to negotiate about the possibilities of joining forces. Both parties saw great potential benefits in the merger of the two largest special steel manufacturers in the Nordic countries: for example, the combination of two kinds of technology — SKF Steel's ingot casting and Ovako's continuous casting technology - and the combination of the two organisations' marketing channels, would both bring advantages.

The owners agreed to establish a new Finnish-Swedish corporation based on joint ownership. The idea of 50-50 ownership arose because neither the Finnish nor the Swedish owners wanted to assume total control or to invest any money in the creation of the new company. Thus, the negotiators simply assessed both the formerly independent companies as being equally valuable. SKF Steel was larger, but Ovako had been more profitable in previous years.

The announcement of the creation of Ovako Steel was made on April 8, 1986. The owners chose a new managing director of Finnish nationality, coming from outside the company. The new top management was then appointed, consisting of more Finnish than Swedish nationals. Seats on the board of directors were divided between representatives of SKF and the Finnish side, with the chairmanship rotating annually between the owners. At the end of 1986 permission for the merger to go ahead was granted by the Finnish and Swedish governments.

Immediately after the merger, plans were made for getting rid of the Koverhar steel mill. This took place at the beginning of 1987, making Ovako Steel a company clearly focusing on special steel production. Several further acquisitions were made between 1987 and 1990, mainly on the finishing side, which was the official strategy advocated in various internal and external forums. Important investments were also made during the same period in the existing units of Imatra, Hellefors and Hofors. As a result Ovako Steel actually grew significantly, as its increasing production capacity and sales volumes showed. Much of this growth was financed by loan capital, as the owners did not want to invest more money in the company. 
What is important for this analysis is that the period between the merger and the final breakup of the corporation was plagued by internal controversy about the future of the main units, which after the divestment of Koverhar were Imatra in Finland, and Hellefors and Hofors, both in Sweden. Table 2 summarises four major issues that were subject to internal debate in Ovako Steel. $^{5}$

Table 2. Issues that were subject to internal controversy in Ovako Steel

Issue Time Content

\begin{tabular}{lll}
\hline Investment project in & $\begin{array}{l}\text { From the merger negotiations } \\
\text { Imatra }\end{array}$ & $\begin{array}{l}\text { The nature and scope of Imatra } \\
\text { stil the end of } 1990 \text { when the }\end{array}$ \\
& steel mill's modernisation project
\end{tabular}

Shutdown of the From the merger negotiations

Hellefors unit until the end of 1990 when the metallurgical unit in Hellefors was finally shut down

The question of the shut-down of the metallurgical unit in Hellefors

Allocation of product From the merger negotiations and production until the end of 1990 responsibilities

Shut-down of the Imatra unit

The question of the complete shutdown of the Hellefors unit

Allocation of product and production responsibilities among the Imatra, Hellefors and Hofors units

From the beginning of 1991 until The question of whether the Imatra the break-up of the corporation
Steel mill should be shut down to enable the corporation to survive the crisis

A central issue that divided the management and the organisation was the investment in Imatra Steel, the basic idea of which was to turn Imatra into an ultramodern production facility based on continuous casting technology. The original plans drafted before the merger 
were revised in various ways during this period. As a result, the project was not completed until the end of 1991.

A related question concerned the possible shut-down of the metallurgical unit of Hellefors, and ultimately of the whole unit, which also led to much debate and divided the management. What happened was that the first tentative decisions made when the company was established were followed by a series of discussions and postponements of the shut-down decision. The final decision to shut down the metallurgical unit was not made until the end of 1990. In the case of the other parts of Hellefors, decisions about new investment in the finishing side of the Hellefors steel mill had been made by the end of 1986 .

Both these issues were also connected with the general issue of the allocation of production and product responsibilities between Imatra and Hellefors and Hofors. Despite several projects launched between 1987 and 1989, no clear consensus was reached on this issue. Imatra and Hellefors in particular continued to compete within the company as regards shortterm supply decisions, and even more so as regards their future responsibilities. Following a long period of rising demand, the demand for Ovako Steel's special steel products collapsed in the summer of 1990. This hit the profitability of the corporation as a whole, which found itself in a deepening crisis. In this situation attention focused increasingly on cost cuts and possible shut-downs. At this stage the issue of shutting down a major unit became a central question that divided the managerial actors. Although preliminary decisions were made about shutting down Imatra, the actors could not make the final decision to do so. Relations between the Finnish and Swedish sides deteriorated even at the top management level. The escalating crisis finally ended in the autumn of 1991 when the owners decided to re-divide Ovako Steel into its component parts. The break-up was announced on November 19th.

In retrospect, it is possible to understand the increasing internal tensions leading to the redivision of the corporation, by examining the emerging roles of the main actors. Although it is a crude distinction, the following sections will concentrate on the enactment of role identities at the owner, the corporate management and the business unit levels. 


\subsection{Enactment of role identities at the owner level: understanding passive participation in internal discussions}

In retrospect the behaviour of the board members, as constituting the board of directors in the first years after the merger, can be interpreted as passive. This gave corporate management considerable freedom when it came to making plans and decisions. In practice, the board the relatively passive owners' representatives - approved most of the plans developed by Ovako Steel's managers, as the minutes of the board meetings of the board and the strategic documents drawn up by corporate management clearly reveal. Specifically, in the case of the internal discussions on the investment project for Imatra, on the shut-down of the Hellefors unit and the allocation of product responsibilities, the owners' representatives refrained from taking up a stand and left corporate management to lead the corporation. A Finnish member of the board put it this way:

With hindsight it is easy to see that we were not the kind of board that would have provided an active discussion forum. Instead, we mostly just sat there [in the board meetings] waiting to be informed about the strategic decisions to be made. I don't think that we were often very critical of the CEO or the corporate management. ${ }^{6}$

This was also the interpretation of most members of corporate management, as the former CEO explained:

We in management could concentrate on the development of the corporation without any problems from the owners. In fact, I would have welcomed a more active attitude on the part of the owners, so that they could also have shared the responsibility for the difficult choices we had to make.

The managers of the business units expressed similar views on the role of the board members. The passive attitude of the Swedish board members, for example, became clear during the early years when the representatives of the Swedish owners failed to provide the support that some of the key managers of Hellefors had hoped for. As a manager from Hellefors put it:

The Swedish owners failed to support us in our efforts to make corporate management see the mistakes they were going to make, for instance, about the shutdown of Hellefors. It was strange to see how the guys who we had previously worked 
with at close range were now hiding behind the backs of the corporate management.

The interviewees were quite clear that the members of the board saw it as their duty to make sure that the interests of the owners would be upheld in the new corporation. In the case of the Finnish owners, this meant specifically the development of an "independent" corporation, as they were looking for possible ways gradually reducing their involvement in the industry. As a Finnish board member put it:

The Finnish side [the owners] was clearly trying to get rid of the business. But we wanted to do so in a controlled way.

To a large extent, the situation in the aftermath of the merger was similar on the Swedish side. The board members, who were members of the corporate management of SKF, wanted to reduce Ovako Steel's dependence on its owners after the merger had taken place. However, steel supplies were important for SKF's main business, namely the production of bearings, as the CEO made plain:

For us, the situation was clear. Now we could concentrate on our core businesses. The steel supplies could be taken care of by a company over which we also had sufficient control through our 50\% ownership.

These divestment ideas obviously go a long way to explaining the limited attention that the owners' representatives paid to Ovako Steel. A Swedish board member put it as follows:

When you have a thousand other responsibilities it's not the company you are going to get rid of that will be your priority.

It is important to note that many of the board members also found it natural to turn to other issues, after the tedious negotiations leading to the merger and the appointment of the new corporate management. A key figure on the Finnish side put it as follows:

You have to understand that from our perspective we had simply done our duty. We had put the pieces together, appointed the corporate management and made the first strategic outline. 
However, the interviews also indicate that the board members seemed to internalise the idea of being the kind of owners' representatives who do not interfere in the management of the corporation. This meant that they almost saw it as their duty to refrain from taking up any particular stand in the internal discussions. A Finnish member of the board put it as follows:

I remember these discussions amongst ourselves [the Finnish board members] where we came to the conclusion that it would be best if we didn't interfere with the internal affairs of the company. Accordingly, I was no longer a Finn supporting the development of the Finnish side but a board member whose primary objective was to see that our [owners'] investments were secured.

Their passive approach, according to the key members of the board, was also a reflection of a willingness to show their confidence in the appointed corporate management. This was seen as important, as they had appointed the new CEO and the corporate management "to build a new Finnish-Swedish corporation”, as indicated in the first strategic plans drawn up after the merger. This point was made by a Finnish board member thus:

As regards the division of work, we obviously gave the CEO and top management the chance to build something new on their own terms.

As the new corporation seemed to be performing well, reporting profits for example, there was no particular reason to become more actively engaged. The owners' representatives, like many of the others involved, shared the view that the profitability of a special steel corporation would be more stable than that of commercial steel companies. A special steel corporation would consequently show lower profitability than commercial steel companies during cyclical upturns, but would be relatively higher during downturns. This attitude was obvious in the discussions during 1988 and 1989, as the former chairman of the board explained:

You live by the logic of performance. When everything is satisfactory you [the chairman] let things continue as they are. When there are problems, then you start to act. At this time [before the collapse of demand], we thought that everything was OK. Although other steel companies were showing greater profits, we were not worried. We believed in the idea that this was only natural for a special steel company. Or at least that was our justification for not taking any action. 
A retrospective interpretation is that the behaviour of the owners' representatives changed radically after the collapse of demand. In this new situation, Ovako Steel was losing money fast. In fact, the entire future of the company and the owners' investments seemed to be at risk. In this difficult situation the owners' representatives wanted to solve the crisis as effectively as possible, "to stop the blood-letting", as word went in the meetings on the Swedish side. ${ }^{7}$ A Finnish board member described this change as follows:

We now had to take matters into our own hands. I started to meet the head of SKF regularly, to get this situation cleared up.

The hands-off approach turned into an active search for solutions to the difficult situation. It soon became clear that external solutions, like cooperation with other steel producers, were no longer possible. Thus, in practice, the owners' representatives were advocating cost cuts and shut-downs within Ovako Steel. Although key individuals representing the owners acted together, the people on both sides were primarily interested in coming up with the best possible solution from their own perspective. The Swedes were actually less interested than the Finns in remaining owners of the seemingly unprofitable Imatra unit, far away from their own roller bearing plants. This point was made by a Swedish board member:

In most cases we [the Swedish and Finnish owners] shared the same views. There was also always a very good atmosphere for working $\cdots$ In this case [the shut-down of Imatra] we ended up with different opinions.

According to the interviews, this also meant increasingly strong identification with the production units in their own countries. A Finnish board member put it as follows:

I remember that when I'd heard the views of the representatives of Imatra, I started to realise the importance of saving the mill. At this stage I think I started to become more a patriot than a rational board member trying to maximise return on investment.

Because of internal disagreements, the shut-down of Imatra never became a reality. The owners' representatives finally concluded that there was no meaningful way of saving the corporation. The Finnish chairman of the board summarised the board's role in the final stages: 
We went back to square one. It was no longer a question of saving the FinnishSwedish corporation, but a situation in which we seemed to have no choice but to redivide the corporation along national lines.

\subsection{Enactment of role identities at the corporate management level: understanding unwillingness to enforce radical changes}

In retrospect, the behaviour of the members of corporate management in the early years can be interpreted as an unwillingness to enforce changes that would be strongly resisted by the core production units - Imatra, Hellefors and Hofors. Consequently, they were ready to back away from some of their original intentions. In practice, this meant being willing to continue with the modernisation project in Imatra in a manner that would take the views of the Swedish managers into account. Corporate management was ready gradually to abandon its plans to shut down the Hellefors unit. Even the shut-down of the metallurgical unit was postponed several times. As regards the allocation of product responsibility, corporate management was also willing to compromise, whenever there was no clear indication of a possible internal consensus. The former CEO described their attitude as follows:

We were ready to modify our plans and to take into consideration the views of the people representing the different units. It was a question of balancing the aspirations of the different people in a manner that seemed most appropriate.

This was how the managers representing the different business units saw things. Retrospectively the Finns were very critical of this approach, as a former head of the Imatra unit made clear:

Corporate management was noticeably very cautious in the internal discussions. From our perspective, it was a question of cowardly behaviour. Time and again the original plans were abandoned and the CEO gave in to the Swedes' demands.

In contrast, many of the Swedish managers from Hellefors and Hofors gave credit to corporate management for this approach. As a key actor from Hellefors put it:

It was a positive thing that corporate management was able to revise some of the original plans, which were extremely one-sided and did not make sense in the new 
conditions [increasing demand]. It's another matter that they should have been more alert to what was going to happen in the long run.

In the aftermath of the merger most members of the corporate management saw themselves as "developers" or "visionaries" in charge of the new developing corporation. The role adopted was described by the new CEO as follows:

We saw ourselves [corporate management] as an active centre responsible for the development of a new special steel company.

Another member of corporate management put it:

We were now facing a great challenge. How to put these pieces together and create a new company. It was our project, not a Finnish or a Swedish project, but Ovako [Steel].

This meant that a great deal of their attention focused on the "strategic development" of the corporation during the first years. It is interesting to note that many members of corporate management connected this later to the fact that at the time such strategic development was almost the norm for the top managements of Finnish or Swedish companies. This orientation was described by a Swedish member of corporate management as follows:

It felt like we were having strategic planning sessions all the time. That was the focus of our work.

What is important is that much of this strategic activity concentrated on further divestments and acquisitions. A member of corporate management described this as follows:

Top management saw itself as a strategic leadership group. We concentrated on the development of a viable future structure for the company. It was up to the units to see that we were operationally competitive.

Again, it is interesting to note that this focus on external issues, according to the interviewees, was also one of the main reasons for the limited attention given to internal problems. One key strategist put it as follows: 
With hindsight it is easy to see how we were caught up in all these plans. This probably meant that we gave too little time to the internal affairs of the corporation.

This work also seemed to bear fruit. For example, the divestment of the Koverhar unit and the new acquisitions made during the period 1987-1990 were regarded as a great success, as can be seen from the strategic planning documents produced by corporate management. A Swedish member of management described their excitement:

I think we were all excited by these dramatic possibilities. And the work seemed really important and successful.

However, the unwillingness to enforce radical changes was also a reflection of an underlying internal division within corporate management. This was pointed out by a Finnish member of management:

Although we had been really united on most questions, the tough internal issues were the ones that I guess fundamentally divided us. Perhaps it was a question of fearing to lose the momentum [within corporate management] that made us avoid them.

This internal division was described by a long-term key strategist as follows:

It was clear that some of the Swedish members had views that differed very much from what we [Finns] had thought and planned. I would not say that we were fighting each other at first. It was more a question of different opinions that we respected.

What is important is that the corporate managers specifically wanted to ensure that no internal problems arising from the confrontation between the Finnish and Swedish sides should disturb the building up of the new corporation. In fact the corporate managers were aiming at the development of a "unified Finnish-Swedish organisation", as various internal documents between 1986 and 1988 expressed it. Their role was described by the former CEO as follows:

We [members of top management] were the referees. We wanted to avoid conflict between Finns and Swedes. We therefore listened very carefully to the messages issuing from the units. 
This avoidance of internal problems was described by a Swedish member of the corporate management:

I personally was aware of a need to distance myself from the internal debate. I was no longer a representative of Hofors but a member of top management. This also meant not taking sides.

It is interesting that the Finnish members of corporate management in particular, who at that time dominated the executive management, were unwilling to make decisions that could be seen as pro-Finnish or unfair from the Swedish perspective. As the former CEO put it:

I think that it was especially important for me and the others [Finns in top management] to show that we were now leading the corporation without our Finnish background affecting our choices.

The idea of not making radical internal changes was to some extent also a conscious choice on the part of corporate management, which was reflected in their clear understanding of the trade-offs involved. This was described by a key strategist as follows:

We certainly understood that by not proceeding more rapidly with the initial strategic plans, we had to sacrifice some of the benefits. I remember many discussions on this issue, in which we clearly recognised that it was the price we had to pay to ensure internal peace within the company.

It should be noted that the business unit managers could also present convincing arguments as to why top management should refrain from making certain specific decisions. For example, the Hellefors managers claimed that it would be irrational to shut down the metallurgical unit in Hellefors, when Ovako Steel needed all the crude steel that could be produced at Hellefors (the new metallurgical unit at Imatra was under construction, and the demand was high at the time).

In retrospect it is easy to see how the collapse on the demand side triggered a fundamental change in the behaviour of corporate management. In this situation their attention was increasingly directed towards "getting the company to survive the crisis", as word went among the corporate managers. When the problems escalated, the rescue of the company 
became the primary objective for corporate management during this difficult time. This idea was expressed by a Finnish member of corporate management as follows:

This was a rescue project. We all wanted to save the company. We still believed in the Finnish-Swedish concept. Later it turned out that we had different views about how to do it.

At the same time, the expectations of the owners were putting additional pressure on the board members, and especially on the new CEO. The owners' representatives were calling for quick solutions. This was not easy, as the CEO explained:

The problem was that the long-term development of the corporation and the measures needed to solve the acute financial crisis were in some conflict with one another.

The corporate managers, who were now being strongly influenced by the owners' representatives, adopted a new approach to the management of the company. Their previous unwillingness to make drastic decisions turned into a readiness to make radical decisions, as a Swedish member of the corporate management recounted:

What was notable was the change in our strategy. Where we had previously been criticised for lack of courage, now we were ready to get things done.

The final decision confirming the shut-down of the metallurgical unit at Hellefors was thus made at the end of 1990. Significant cost cuts were planned and implemented at the end of 1990 and during 1991. By the spring of 1991, it was apparent to the corporate top managers that even more radical decisions were needed to rescue the company. In practice this meant planning for the shut-down of one of the major production units, of which Imatra appeared to be the most unprofitable.

Adopting a more decisive role in the internal discussions was not easy, however. Ironically, many people could see that in the heated internal atmosphere there were even stronger demands on corporate management to act as "referees" and to avoid taking sides. The conflicting expectations imposed upon the corporate management were described by a Finnish member as follows: 
It was very difficult. We knew that very clear and determined action was needed to solve the crisis. At the same time there was this incredible internal conflict between the Finns and Swedes in which we obviously could not take sides.

According to the interviews the outcome was that corporate management became increasingly divided along the original Finnish-Swedish lines. This situation was commented on by a Finnish member of corporate management when he described crucial meetings in the spring and summer of 1991:

It was interesting to see how the [Finnish-Swedish] division became very visible in our work for the first time. At this stage we [Finns] were the minority. It was clear that we could no longer work as an effective [corporate] management.

\subsection{Enactment of role identities at the business unit level: understanding internal politicking}

In retrospect the behaviour of the key managers representing the core production units can be interpreted as an increasing identification with the interests of their own units and participation in the related internal politicking. A Swedish manager representing Hofors put it as follows:

I think that over time we became more and more clearly involved in these internal struggles. The reason was that there was so much at stake.

His colleague from Imatra said:

This was a case when we did not become friends. It was more that both the Swedes and us Finns learned to campaign for our own interests.

Members of corporate management held similar views, as expressed by the former CEO:

I think that over time the situation became clear. People on both sides started concentrating on lobbying for their own causes. With hindsight it's easy to see that it was our mistake. We let it happen without blowing the whistle.

In the aftermath of the merger many managers on the Swedish side regarded the situation as threatening. The first plans meant that a great deal of money would be invested in the Imatra production unit, and that the metallurgical unit at Hellefors - perhaps the whole unit in the 
long run — would be shut down, which was difficult for the Hellefors people to understand. The Hellefors and Hofors managers were united, in that neither of them wanted Imatra and its continuous casting technology to invade their territory, which was the production of bearing steel by mastering the ingot casting technology. A former head of the Hofors unit described the situation:

It would be false to say that we [key managers on the Swedish side] were unanimous. On this issue [the idea of Imatra producing bearing steel], however, there was a common front.

Thus the behaviour of several key people representing Hellefors and Hofors was characterised by strong resistance to change during those first years. One of the actors at Hellefors described his own actions as follows:

In this situation it was my duty to see that corporate management didn't make foolish decisions. I, like my colleagues, reasoned that if we didn't stand up against these plans, no one would.

What was important was that they also succeeded in many of their efforts, such as burying the idea of the complete shut-down of the Hellefors unit, postponing the possible shut-down of the metallurgical unit, revising the plans for the investments in Imatra and avoiding excessively radical decisions about product responsibility in favor of Imatra. The head of Hellefors put it as follows:

We were doing nothing wrong. It was good that our points of view were taken into account in these discussions.

From the perspective of the Finnish business unit managers, the merger appeared to be offering a major opportunity. It was especially important for them that the new FinnishSwedish constellation seemed to be securing the financing for the big investments in Imatra. They wanted to see the Imatra steel mill turn into a large modern production unit, responsible for much of the crude steel processing and special steel production within the new FinnishSwedish constellation. This was described by a key actor on the Finnish side as follows:

We were definitely looking forward to making this [the Imatra unit] a world-class 
production unit that would secure employment for the future.

In this situation it was natural for the Finnish business unit managers to support corporate management's ideas. At first, however, instead of being particularly active in relations with corporate management, the Finns expected top managers to take care of such central decisions, which they thought had been agreed upon when the company was established. The former head of the Imatra steel mill put it as follows:

We were all for the new corporation at that stage. And I think that I for example saw myself as a corporate man rather than someone representing Imatra. Later this changed of course.

To the disappointment of the Finns, however, the original plans did not materialise. As a result the key managers of the Imatra unit in particular launched a more planned lobbying campaign at corporate headquarters. This change in behaviour was described as follows by the former CEO of the corporation:

I think it was a question of learning. They realised they would have to be more active about getting their voices heard.

It should be noted, however, that not all managers on the Finnish or Swedish sides became active lobbyists in their relations with corporate management. For example, one key manager on the Finnish side commented on his own role:

I know that many people at Imatra were disappointed that I didn't support their views. However, I saw it as my duty to follow the strategies developed by corporate management.

On the Swedish side, on the other hand, certain key managers adopted the active role while others were more concerned about corporate unity. One key manager at Hofors described their roles in the internal discussions thus:

I think that certain people had clear missions, especially at Hellefors. Others, like me, were less clear about what we could or should do. 
In retrospect it is obvious how the collapse of demand intensified the internal politicking. In this situation the futures of the core production units were at stake. Consequently, the Swedish business unit managers continued to campaign against ideas that they saw as particularly destructive. The head of the Hellefors unit described these efforts as follows:

I'm not sure that I would call it resistance. What we did was to make sure that our points of view were heard and understood by all the decision makers.

To their disappointment, corporate management made the final decision to shut down the metallurgical unit at Hellefors at the end of 1990. From this point on, it became particularly important for both the Hellefors and Hofors managers to make sure that new shut-downs would not hit the core units of the Swedish organisation. In practice, this meant that the Swedes began to push with increasing force for the shut-down of the Imatra steel mill, as this remained the most natural alternative from where they stood. Their arguments were described by a member of the corporate management in the following way:

The Swedish representatives had a definite agenda. They wanted to close down Imatra. Their argument was clear: Imatra was the most unprofitable unit. And it was close to the Russian border, far away from the customers.

What made the situation particularly grave for the Finnish managers was that the future of the Imatra Steel mill, the core of the Finnish organisation, was suddenly being threatened. The culminating event that evoked strong resistance among the Finnish business unit managers was the announcement of the plan to shut this unit down. In this situation the Finnish unit managers launched a powerful campaign to save the Imatra steel mill. This was described by the head of the Imatra steel mill as follows:

What we [the management of the Imatra steel mill] had to do was to change from supporters of their [corporate management's] plans, and become fighters. We were fighting for the future of our plant and also for the future of Finnish steel production.

The Finns consequently made a special effort to try to change the minds of the other decision makers. The change in their behaviour was described thus by the new CEO of the corporation: 
This was a remarkable change. They suddenly formed an internal resistance movement $\cdots$ What was most impressive was that they were now all speaking with one voice.

At this stage the behaviour of the unit managers became openly antagonistic toward the other side, as key actors in Finland and Sweden came to regard each other as "opponents” or “enemies”. For example, the Finns became increasingly inclined to regard their Swedish colleagues as responsible for the shut-down plans that were threatening Imatra. As one Imatra manager put it:

I think the name of the game was obvious at this stage. They wanted to shut down Imatra in order to survive. We on the other hand were looking for cutbacks on their side, and we found them.

It is interesting to note that at this stage the managers and the other employees in the respective business units seem to have been forming a more united front than before. The most famous example of a unanimous open confrontation was probably an incident in them spring of 1991 when trucks were sent to transfer part of Imatra's production machinery to Sweden. The Finns refused to let the trucks enter the production site. The head of the Imatra unit described his role in this incident:

It was a natural reaction. In this situation, I personally no longer felt any obligation

to take care of the company's [the corporation's] interests. Although I was not actually there at the gate, I was certainly there in spirit.

\section{Understanding the emergence of internal sociopolitical forces through role-bound behaviour}

The case of Ovako Steel clearly illustrates how decision makers in the upper echelons of a corporate hierarchy can be divided in many ways in post-merger organisational change processes. In this case the various actors tended increasingly to internalise the idea of becoming agents pursuing the interests of the owners, the corporation or the business units. In retrospect it is easy to see how the ongoing internal discussions sustained and strengthened these internal divisions. This, it is interesting to note, also meant an increasing acceptance 
and legitimisation of overt political behaviour. While this type of situation may well characterise many corporations, horizontal mergers are particularly likely to mean that the achievement of the desired synergistic or other benefits will create the anticipation of changes that are likely in turn to be interpreted in very different ways in different places.

This analysis provides some insights into the emerging roles in the upper echelons of hierarchy. Looking at the "gestalts" of the owners' representatives, the corporate managers and the business unit managers helps us to understand how the internal division after a corporate mergers is reflected in decision-making processes in the upper echelons of a hierarchy. It is important to note that the way the actors enacted their roles was highly situation-specific. The behaviour appropriate to a corporate manager or to the securing of the future of a manager's own particular unit, was constantly being redefined by the relevant actors.

The historical case of Ovako Steel also reveals role-specific tendencies that may appear rational from the perspective of the particular actors, but may have pathological consequences for the new post-merger organisation. As regards the owners' representatives, this case highlights the risks of passive participation in corporate decision making. As regards the corporate managers, the analysis reveals the severe consequences of an unwillingness to enforce radical changes. And as regards the business unit managers, the case draws attention to the problematic consequences of internal politicking.

We have seen how the owners' representatives can easily adopt a passive attitude in postmerger change processes, and this may then prevent them from detecting fundamental problems in the corporation. This finding is consistent with the classical argument that the owners should become a force for control vis-à-vis corporate management. This type of passive stance may be fairly natural after the tedious negotiations that culminate in a merger decision (see Duhaime and Schwenk, 1985; Jemison \& Sitkin, 1986; Haunschild, DavisBlake \& Fichman, 1994). Ironically, it is thus often likely that the principal architects of mergers are not themselves very actively involved in making the important organisational decisions once the merger has taken place. This also provides an interesting explanation for the common experience that mergers often fail to provide the kind of results that were expected by the original architects. 
This analysis shows further that not being too active may be regarded as a justifiable way of showing confidence in the newly appointed corporate management, by not interfering too much in their work. This may be a common tendency specific to mergers as opposed to acquisitions, since mergers usually imply a need to develop a new corporate culture and identity that can be readily distinguished from the previously separate organisations or that can transcend national divisions (see also Olie, 1996). The passive attitude may also be connected with divestment aspirations, as this case clearly shows. While ideas about divestment may not be the most common motive for mergers, it is worth remembering that they are in fact the motivation behind a great many of the mergers in traditional industries such as steel manufacturing. The passive stance may also be a special risk in the context of 50-50 ownership, where neither party can easily assume control.

The case also shows how corporate management may become unwilling to enforce radical decisions, which can lead to a failure to achieve synergistic benefits or to cope with internal conflicts. This is consistent with the empirical analyses in Kleppestø (1993) which studies a Swedish merger, and in Olie (1994) which looks at three Dutch-German mergers. The findings of both of these also illustrate how an unwillingness to make radical changes actually promotes internal conflicts of interest. This type of behaviour is obviously linked to the fact that corporate management may itself be divided along organisational lines (e.g. Kleppestø, 1993; Greenwood et al., 1994) or national borders (e.g. Olie, 1994; Very, Lubatkin, Calorif \& Veiga, 1997). This is clearly a problem specific to mergers, where there is a natural tendency to build the corporate management on a "balance of power" principle, which implies a division according to previous organisational or national boundaries as described in Hambrick and Cannella (1993) or Very et al. (1997).

This tendency is also connected with pressure on corporate management to win the support of the organisation and to create a positive atmosphere for cooperation. Ironically, such an approach, i.e. "making cautious changes", is also the common advice of the human resource or culturally orientated researchers, who advocate listening to the organisations' concerns and being cautious about making changes in order to avoid problems arising from resistance in the work-force (Buono \& Bowditch, 1989). It has also been shown here how such unwillingness to enforce radical changes can be interpreted as a focus on external issues. In fact, the case has suggested that an externally orientated development of the corporation through strategic moves such as divestments and further acquisitions, can provide an escapist 
way of withdrawing from the more problematic internal issues. In other words we have a clear example of actors looking for areas in which they can feel they are succeeding (Levinthal \& March, 1993).

The case also reveals how the business unit managers, identifying themselves with the interests of their own units, can become powerful agents of internal politicking, reinforcing the internal divisions and causing relations to deteriorate. Here the present analysis has identified an important mechanism linking organisational-level fears, anxieties and ambitions - a topic that has been studied quite extensively in this field (Buono \& Bowditch, 1989,Fried et al., 1996,Lohrum, 1996) — with corporate-level decision making concerning organisational integration. Such behaviour on the part of unit managers is often likely to occur in horizontal mergers that combine former competitors, thus internalising the competition. It need not necessarily be a question of clearly articulated plans directly affecting the units concerned that may activate their managers to lobby for them. This kind of behaviour can also stem from the anticipation of future changes or from mixed expectations of future resource-allocation games. Identification with the interests of a unit is likely to be particularly strong in industries where the production units are an integral part of the local community. In traditional industries such as steel manufacturing, threats affecting the future of these units have heavier implications than in some other industries. It is thus easy to understand how managers working for such units may become actors specifically motivated to fight for their futures.

Finally, the analysis brings out the importance of taking context into account when examining the behaviour of decision makers in post-merger processes of organisational change. Specifically, it has been shown that a favourable turn in the business cycle after a merger can give the actors a false belief in a healthy state of affairs. In the present case, satisfactory profitability gave the actors signals of success that drew their attention away from the severity of the internal problems in the corporation, thus making things even worse. It is easy to see how all this affected the behaviour of the owners' representatives and corporate management in particular. This is an important finding which suggests that merger decisions followed by a favourable turn in the business cycle are likely to be especially risky, and that successful profitability development may actually impede successful integration. ${ }^{8}$ 


\section{Conclusion}

This article represents an attempt to understand post-merger organisational change processes by focusing on internal decision making. The study offers a clear description of internal divisions in the upper echelons of a corporate hierarchy, thus casting serious doubt on the literature in this field that reflects the assumption that top management can act as a unified agency striving for the achievement of specific integration objectives (Hunt, 1990; Larsson, 1990; Haspeslagh \& Jemison, 1991). The analysis also demonstrates that it is not enough to focus exclusively on the basic division between those who identify themselves with the previously separate organisations, which has been the conceptual starting-point for much research in this field (Buono \& Bowditch, 1989; Greenwood et al., 1994; Olie, 1994; Pablo, 1994). Rather, it is argued that the emerging role structure in the upper echelons of a corporate hierarchy is very important to an understanding of sociopolitical forces that are at work there.

In future studies in this field, it is therefore necessary to proceed to the specifics of different types of setting, rather than to fall back on vague rhetoric about "the management of the integration process”. Future studies could in fact go further and seek to distinguish different types of positions, roles and identities for the central actors involved in these processes. In particular it would be interesting to concentrate on individual people's perceptions of role conflict and ambiguity in settings less clear cut than in this special case. While this study has been an attempt to examine the historical experiences of the central actors, future studies could try to identify different epistemological layers in these processes. Retrospective reconstruction, telling different types of stories about the processes, could in itself be taken as a serious research question in studies of this kind.

The results of the present analysis also have managerial implications. The owners' representatives in particular should be aware of the risks involved in remaining passive in corporate decision making; the members of corporate top management should recognise the risks involved in failing to enforce radical changes; the business unit managers should recognise the harmful consequences of internal politicking; and all the actors concerned should be aware of the risk of conflicting interests at the business unit level and the illusions triggered by a favourable turn in the business cycle. 
There is reason to believe that the exaggerated confidence in unified management in earlier studies has led to an over-optimistic view of the organisational consequences of merger decisions, and specifically of the managerial ability to control the relevant change processes. As this analysis has shown, managers can be regarded as actors playing different types of role in the course of the ongoing change processes, rather than as playwrights. They may often be acting under the illusion of being in control, just because they have failed to understand fully the parts that they and others are playing, or to comprehend in full the effects of their actions in a wider context. In view of this, it seems appropriate to conclude by asking ourselves whether merger decisions would be as popular as they are today, if the decision makers had a more realistic understanding of their own ability to control the change processes.

\section{References}

Alasuutari, P. (1995). Researching culture: Qualitative method and cultural studies, Sage, London.

Altendorf, D.M. (1986). When cultures clash: A case study of the Texaco takeover of Getty Oil and the impact of acculturation on the acquired firm, University of Southern California, Los Angeles.

Ashforth, B.E. and Mael, F. (1989). Social identity theory and the organisation. Academy of Management Review, 14, pp. 20-39.

Barley, S.R.(1990). Images of imaging: Notes on doing longitudinal fieldwork. Organisation Science, 3 , pp. 220-247.

Bastien, D.T. (1987). Common patterns of behaviour and communication in corporate mergers and acquisitions. Human Resource Management, 26 , pp. 17-33.

Berle, A.A. and G.C. Means, (1932). The modern corporation and private property, Commerce Clearing House, New York.

Buono, A.F. and J.L. Bowditch, (1989). The human side of mergers and acquisitions. Managing collisions between people, cultures, and organisations, Jossey-Bass, San Francisco.

Cartwright, S. and C.L. Cooper, (1993). The psychological impact of merger and acquisition on the individual: A study of building society managers. Human Relations, 46, pp. 327-347. 
Chandler, A. (1997). The visible hand, Harvard University Press, Cambridge, MA (1977).

Chatterjee, S. and M. Lubatkin, (1990). Corporate mergers, stockholder diversification, and changes in systematic risk. Strategic Management Journal, 11, pp. 255-268.

Datta, D.K. (1991). Organisational fit and acquisition performance: Effects of postacquisition integration. Strategic Management Journal, 12 , pp. 281-297.

Duhaime, I.M. and C.R. Schwenk, (1985). Conjectures on cognitive simplification in acquisition and divestment decision making. Academy of Management Review, 10, pp. 287295.

Dutton, J.E. and J.M. Dukerich, (1991) Keeping an eye on the mirror: Image and identity in organisational adaptation. Academy of Management Journal, 34, pp. 517-554.

Dutton, J.E., S.J. Ashford, R.M. O'Neill and E.E. (1997) Wierba, Reading the wind: How middle managers assess the conditions for selling issues to top management. Strategic Management Journal, 18, pp. 404-425.

Fondas, N. and R. Stewart, (1994). Enactment in managerial jobs: A role analysis. Journal of Management Studies, 31, pp. 83-103.

Fried, Y., R.B. Tiegs, T.J. Naughton and B.E. Ashford, (1996). Managers' reactions to a corporate acquisition: A test of an integrative model. Journal of Organisational Behaviour, 17, pp. 401-427.

Golden, B.R. (1992). The past is past - or is it? The use of retrospective accounts as indicators of past strategy. Academy of Management Review, 35, pp. 848-860.

Golden, B.R. (1997). Further remarks on retrospective accounts in organisational and strategic management research. Academy of Management Journal, 40, pp. 1243-1252.

Goold, M. and A. Campbell, (1987). Strategies and styles, Blackwell, Oxford.

Greenwood, R., C.R. Hinings and J. Brown, (1994). Merging professional service firms. Organisation Science, 5, pp. 239-257.

Guth, W.D. and I.C. MacMillan, (1986). Strategy implementation versus middle management self-interest. Strategic Management Journal, 7, pp. 313-327. 
Hambrick, D. and A. Cannella, (1993). Relative standing: A framework for understanding departures of acquired executives. Academy of Management Journal, 36, pp. 733-762.

Haspeslagh, P.C. and D.B. Jemison,(1991). Managing acquisitions, The Free Press, New York.

Haunschild, P.R., A. Davis-Blake and M. Fichman, (1994). Managerial overcommitment in corporate acquisition processes. Organisation Science, 5, pp. 528-540.

Hunt, J.W. (1990). Changing pattern of acquisition behaviour in takeovers and the consequences for acquisition processes. Strategic Management Journal, 11, pp. 69-77.

Ingham, H., I. Kran and A. Lovestam, (1992). Mergers and profitability. Journal of Management Studies, 29, pp. 195-208.

Jemison, D. and S. Sitkin, (1986). Corporate acquisitions: A process perspective. Academy of Management Review, 11, pp. 145-163.

Katz, D. and R.L. Kahn, (1978). The social psychology of organisations, John Wiley, New York.

Kitching, J. (1967). Why do mergers miscarry? Harvard Business Review, 46, 84-101..

Kleppestø, S. (1993). Kultur och identitet vid företagsuppköp och fusioner, Nerenius and Santérus förlag, Stockholm.

Larsson, R. (1990). Coordination of action in mergers and acquisitions. Interpretive and systems approaches towards synergy, Lund University Press, Lund.

Levinson, H. (1970). A psychologist diagnoses merger failures. Harvard Business Review, 48, pp. 139-147.

Levinthal, D.A. and J.G. March, (1993). The myopia of learning. Strategic Management Journal, 14, pp. 95-112.

Lewin, (1951). Field theory in social science, Harper and Brothers, New York.

Lohrum, C. (1996). Postacquisition integration Towards an understanding of employee reactions, Swedish School of Economics and Business Administration, Helsinki. 
March, J.G. and J.P. Olsen, (1989). Rediscovering institutions. The organisational basis of politics, The Free Press, New York.

Marks, M.L. and P. Mirvis, (1985). Merger syndrome. Mergers and Acquisitions, 20, pp. 5055.

Mead, G.H. (1934). Mind, self and society, University of Chicago Press, Chicago.

Merton, R.K. (1957). The role set. British Journal of Sociology, 8, pp. 106-120.

Miller, S.J., D.J. Hickson and D.C. Wilson, (1996). Decision-making in organisations, S.R.

Clegg, C. Hardy, W.R. Nord, Editors, Handbook of organisation studies, Sage, London.

Mintzberg, H. (1985). The organisation as a political arena. Journal of Management Studies, 22, pp. 135-154.

Nahavandi, A, and A.R. Malekzadeh, (1988). Acculturation in mergers and acquisitions. Academy of Management Review, 13, pp. 79-90.

Napier, N.K. (1989). Mergers and acquisitions, human resource issues and outcomes: A review and suggested typology. Journal of Management Studies, 26, pp. 271-289.

Napier, N.K., G. Simmons and K. Stratton, (1989). Communication during a merger: Experience of two banks. Human Resource Planning, 12, pp. 105-122.

Nkomo, S.M. and T. Cox, (1996). Diverse identities in organisations, S.R. Clegg, C. Hardy, W.R. Nord, Editors, Handbook of organisation studies, Sage, London.

Olie, R. (1990). Culture and integration problems in international mergers and acquisitions. European Management Journal, 8, pp. 206-215.

Olie, R. (1994). Shades of culture and institutions in international mergers. Organisation Studies, 15, pp. 381-405.

Olie, R. (1996)., European transnational mergers, Proeschrift Rijskuniversiteit Limburg, Maastricht.

Park, R.E. (1927). Human nature and collective behaviour. American Journal of Sociology, 32, pp. 695-703.

Parsons, T. (1951). The social system, The Free Press, Glencoe, IL. 
Pablo, A. (1994). Determinants of acquisition integration level. Academy of Management Journal, 37 , pp. 803-836.

Perry, L.T. (1986). Merging successfully: Sending the right signals. Sloan Management Review, 27 , pp. 47-57.

Pettigrew, A.M. (1973). The politics of organisational decision making, Tavistock, London.

Porter, M.E. (1987). From competitive advantage to corporate strategy. Harvard Business Review, 65, pp. 43-59.

Pritchett, P. (1985). After the merger, Dow Jones-Irwin, Homewood, IL.

Sales, A.L. and P.H. Mirvis, (1984). When cultures collide, J. Kimberley, R. Quinn, Editors , New futures, Dow Jones-Irwin, Homewood.

Sayer, A. (1992). Method in social science. A realist approach, Routledge, London.

Schweiger, D.M., J.M. Ivancevich and F.R. Power, (1987). Executive action for managing human resources before and after acquisition. Academy of Management Executive, 1, pp. 127-138.

Schweiger, D.M. and A.S. DeNisi, (1991). Communication with employees following a merger: A longitudinal field experiment. Academy of Management Journal, 34, pp. 100-135.

Scott, W.R. (1995). Institutions and organisations, Thousand Oaks, Sage.

Shrivastava, P. (1986). Post-merger integration. Journal of Business Strategy, 7, pp. 65-76.

Tainio, R., Lilja, K., \& Räsänen, K. (1984). Management and modern corporation in society: How are they interrelated?. Working paper F-98. Helsinki School of Economics, Helsinki..

Tainio, R., K. Räsänen and T. Santalainen, (1987). Suuryritykset ja niiden johtaminen Suomessa: Liiketoiminnan johtamisesta yhtymän strategiseen johtamiseen, Weilin + Göös, Helsinki.

Tajfel, H. and J.C. Turner, (1979). An integrative theory of intergroup conflict, W.G. Austin, S. Worchel, Editors, The social psychology of intergroup relations, Brooks/Cole, Monterey, CA. 
Teulings, A. (1986). Managerial labour processes in organised capitalism, D. Knights, H. Willmott, Editors, Managing the labour process, University Press, Cambridge.

Tsoukas, H. (1989). The validity of idiographic research explanations. Academy of Management Review, 14, pp. 551-561.

Turner, R.H. (1985). Unanswered questions in the convergence between structuralist and interactionist role theories, S.N. Eisenstadt, H.J. Helle, Editors , Perspectives on sociological theory: Micro-sociological theory, Sage, London.

Very, P., M. Lubatkin, R. Calori and J. Veiga, (1997). Relative standing and the performance of recently acquired European firms. Strategic Management Journal, 18, pp. 593-614.

Walter, G. (1985). Culture collisions in mergers and acquisitions, P. Frost, G. Moore, M. Reis Louis, C. Lundberg, J. Martin, Editors , Organisational culture, Sage, Beverly Hills.

Weber, Y., O. Shenkar and A. Raveh, (1996). National and corporate cultural fit in mergers/acquisitions: An exploratory study. Management Science, 42, pp. 1215-1227.

Williamson, O. (1996). The mechanisms of governance, Oxford University Press, New York.

\section{NOTES}

${ }^{1} \mathrm{~A}$ `merger’ is understood here as a combination of organisations of fairly similar size, which creates an organisation where neither party can clearly be seen as the acquirer. This article concentrates specifically on mergers where the ownership in the new company is divided on a 50-50 basis between the previous owners of the merging organisations.

${ }^{2}$ Identities are individuals' cognitive categorisations of themselves as members of broadly recognised socially defined categories (see Tajfel \& Turner, 1979; Ashforth \& Mael, 1989 B.E. Ashforth and F. Mael, Social identity theory and the organisation. Academy of Management Review, 14 (1989), pp. 20-39. In the vast array of different types of identity, ‘role identities’ are particularly important for organisational actors.

${ }^{3}$ This partly explains a common trend whereby many social scientists have discarded the concept of 'role’ in favour of 'identity'. The strength of the 'role’ concept, however, lies in its close connection with behaviour. 
${ }^{4}$ To acquire a good understanding of the case, several other people who were not managerial decision makers were also interviewed. They included consultants involved in the acquisition or the merger process, industry experts and union representatives.

5`Issues` are seen here as questions that provoke the attention of organisational members (see also Dutton \& Dukerich, 1991, pp. 518-519).

${ }^{6}$ All quotations are my translations from Finnish or Swedish.

${ }^{7}$ It should be noted that the problems the Finnish and Swedish parent companies were facing as a result of the dramatic start of a recession in Scandinavia greatly increased the pressure to find a solution to the crisis.

${ }^{8}$ It is interesting to note that this mechanism, whereby financial success impedes integration, has received virtually no attention in the literature in this field. Rather, the model according to which successful integration creates benefits that are then reflected in improved financial performance dominates the literature (see e.g. Porter, 1987; Chatterjee \& Lubatkin, 1990; Haspeslagh \& Jemison, 1991; Larsson, 1990; Pablo, 1994). This is a major issue calling for future research in this field. 